\title{
Borderline personality disorder in children and adolescents: discriminant validity in relation to major depressive disorder
}

\author{
Khrista Boylan ${ }^{1,2 *}$, Lisa Dyce ${ }^{1,3}$ and Valbona Semovski ${ }^{1,4}$ \\ ${ }^{1}$ Departments of Psychiatry and Behavioural Neurosciences, Canada \\ ${ }^{2}$ Health Research Methods, Evidence and Impact, McMaster University, Hamilton Ontario, Canada \\ ${ }^{3}$ McMaster Integrative Neuroscience Discovery and Study (MiNDS) Graduate Program, McMaster University, Hamilton Ontario, Canada \\ ${ }^{4}$ Holland Bloorview Kids Rehabilitation Hospital, Toronto Ontario, Canada
}

\begin{abstract}
Clinical discernment of the diagnosis of borderline personality disorder (BPD) in adolescents is difficult, due in part to very high rates of comorbidity with major depressive disorder (MDD) or depressive symptoms. This paper reviews published research (1980-2017) on studies about risk factors, neurobiological and neuropsychological correlates and treatment in both disorders for persons less than 25 years of age. The aim is to focus on differences identified between the disorders to substantiate their discriminative validity, although similarities are included. Very few studies were found which directly compared youth with both disorders - or both disorders - in the same sample. These studies found strong covariation between BPD and MDD symptoms across adolescence and conjoint response to dialectical behavioural therapy. Youth with BPD may have greater impairments in social processing than youth with MDD. Indirect comparisons supported poor evidence for discriminative validity and no findings were replicated. To date, the limited research base does not support that BPD and MDD are distinct disorders in adolescence, however the absence of observed differences is not the same as evidence of no difference. Given the importance of improving psychiatric and psychological care for youth, it is strongly recommended that studies about adolescent mood and mood disorder include concurrent and repeated measurement of BPD and MDD.
\end{abstract}

\section{Introduction}

Recent years have seen a surge in research supporting the validity of the diagnoses of borderline personality disorder (BPD) in adolescents. The persistence of symptoms for meeting diagnostic threshold for BPD has been shown to be as stable in youth as in adult samples [1$3]$ and BPD in adolescents shares similar predictors and outcomes to the disorder in adults $[2,4]$. For important comorbidities such as attention deficit hyperactivity disorder (ADHD) and post-traumatic stress disorder (PTSD), evidence of discriminant validity has also been shown $[5,6]$. Studies of evidence-based psychotherapies for BPD in adults demonstrate that such interventions are also successful in youth populations that have 3 or more symptoms of BPD, and the longest follow-up study of treatment is now 12 months [7]. The view from the field is that is important to diagnose BPD in youth who meet clinical criteria for the diagnosis, and offering evidence-based interventions for BPD earlier in life could be a major public health intervention.

In contrast, there is strong reluctance to diagnose BPD in youth, much of which is due to stigma associated with the diagnosis [8], and the relatively recent changes to The Diagnostic and Statistical Manual of Mental Disorders (DSM) permitting the diagnosis of personality disorders prior to age 18 [9]. Adding to their reluctance is the common problem facing clinicians concerning the high rate of comorbidity between depressed mood or a major depressive episode and BPD. It is likely that clinician willingness to assess and diagnose BPD in adolescents would be increased were it more certain that BPD is distinct from MDD - particularly for those youth with suicidal thoughts and behaviours.

Adult studies have shown that while there is indeed substantial overlap or comorbidity between BPD and MDD $[10,11]$ these are likely distinct clinical phenotypes. Goodman, et al. [12] reviewed evidence for discriminant validity of BPD and MDD in adults and concluded that they are independent disorders with overlapping biological mechanisms associated with emotion regulation. Specifically, these authors note that the key distinguishing factor for BPD is the sensitivity to affective shifts which are more transient and reactive as opposed to the sustained mood problems seen in MDD. Overlapping biological processes including amygdala hyperreactivity, volume changes in subgenual anterior cingulate cortex, and deficient serotonergic function appear to underlie emotional dysregulation in both disorders. However, the disorders seem to differ in their patterns of brain region involvement, neurohormonal indices, and sleep architecture [12].

It is important to explore evidence for distinctness of these disorders in youth for several reasons. First, it is possible that these diagnoses are less distinct in terms of presentation, course, correlates and outcomes during adolescence than in adulthood [13]. For example, the majority of youth with depression engage in self-injurious or suicidal thoughts and behaviours [14,15] also seen in adolescents with BPD. Many depressed youths also report several years of dysphoric mood and indeed other psychiatric disorders prior to onset of depressed mood

Correspondence to: Khrista Boylan Ron Joyce Children's Centre. 327 Barton Street East, Room 315, Hamilton Ontario, Canada, Tel: (905) 521-2100-77250; E-mail: boylank@mcmaster.ca

Key words: borderline personality disorder, major depressive disorder, adolescent, youth, review, validity

Received: December 02, 2017; Accepted: December 26, 2017; Published: December 30, 2017 
making age at onset difficult to establish. Although no study of youth with MDE has specifically reported this, it is likely that depressed adolescents commonly experience core features of BPD, such as identity disturbance and rejection sensitivity, as well. The mean age at onset of a depressive episode in adolescents occurs around age 14 or 15 [16] making it a critical age where sadness may be linked to emotional impulsivity, manifesting as BPD or subthreshold BPD symptoms.

The aim of this paper is to review and synthesize existing evidence supporting the discriminant validity of BPD as compared to MDD in the adolescent age group. While significant data has accumulated to support the construct validity of BPD in youth, the specificity of its risk factors and correlates from MDD has not been systematically evaluated. Without strong evidence to support the distinctness of BPD and depression in adolescents, clinicians will continue to be hesitant to diagnose BPD and primary and secondary prevention efforts will remain significantly compromised. Further, there is strong evidence from adult studies that comorbid disorders may not improve until BPD is recognized and treated [17], emphasizing the importance of diagnosis of BPD with other conditions when it is present.

\section{Methods}

Following the approach of Robins and Guze [18] which delineated the criteria for psychiatric syndromes, we compared BPD and MDD across the features of phenomenology, epidemiology, symptom course, risk factors, laboratory measures (neurobiology, neuropsychology) and treatment response. Our intent was to present data on each of these syndrome criteria areas from studies in youth $(<25$ years old).

We conducted our search for articles using Web of Science, Pubmed, Google Scholar and PschINFO with the keywords "borderline personality", "major depressive disorder", "depression", "adolescen””. We included articles published between 1980 and September 2017. We read the abstracts of English language articles to ascertain whether the study included human subjects aged less than 25 years of age, and provided data regarding the aims of the research. When unclear, the papers were read for confirmation, and we consulted the references cited by the primary articles for papers not identified during the literature search.

In each section, we present data from studies of adolescent BPD, followed by studies of adolescent MDD, and then, where available, studies where BPD and MDD symptoms or disorders were compared in the same sample. Each section contains a summary of evidence of distinctiveness and similarities between the conditions.

\section{Phenomenology \& Epidemiology}

BPD: The DSM-5 lists nine criteria for BPD, five of which must be met to warrant a BPD diagnosis (Table 1) [9]. Recent studies have documented similar estimates of reliability and validity of BPD in both adolescent- and adult-aged samples [8,19].

The community prevalence of BPD in adolescents is estimated to be $3 \%$, with $7.8 \%$ of adolescents having moderate severity of the disorder (3 or more symptoms) [20]. Clinical prevalence ranges between 10$20 \%$ in outpatient psychiatric settings and upwards of $50 \%$ in inpatient settings [21]. In clinical settings, there is a female preponderance with a 3:1 ratio of females to males with BPD; in community samples, there are no significant gender differences reported with a ratio of 1:1 [21].

Rates of psychiatric comorbidities for adolescents with BPD resemble those cited in the adult BPD literature [22,23]. In adolescence, BPD is highly comorbid with depression (71.4\%), anorexia (40.2\%),

\section{Table 1. DSM-5 Criteria for BPD [9]}

A pervasive pattern of instability in interpersonal relationships, self-image, and affects, and marked impulsivity, beginning by early adulthood and present in a variety of contexts, as indicated by five (or more) of the following:

1. Frantic efforts to avoid real or imagined abandonment.

1. (Note: Do not include suicidal or self-mutilating behavior covered in Criterion 5.)

2. A pattern of unstable and intense interpersonal relationships characterized by

2. extremes of idealization and devaluation.

3. Identity disturbance: markedly and persistently unstable self-image or sense of 3. self.

Impulsivity in at least two areas that are potentially self-damaging (eg. spending,

4. sex, substance abuse, reckless driving, binge eating).

(Note: Do not include suicidal or self-mutilating behavior covered in Criterion 5.)

5. Recurrent suicidal behavior, gestures, or threats, or self-mutilating behavior.

Affective instability due to a marked reactivity of mood (eg. intense episodic

6. dysphoria, irritability, or anxiety lasting a few hours and rarely more than a few days).

7. Chronic feelings of emptiness.

8. Inappropriate, intense anger or difficulty controlling anger (eg. frequent displays

8. of temper, constant anger, recurrent physical fights.)

9. Transient, stress-related paranoid ideation or severe dissociative symptoms.

\section{Table 2: DSM-5 Criteria for MDD [9]}

\begin{tabular}{|c|c|}
\hline Criterion A & $\begin{array}{l}\text { Five (or more) of the following symptoms have been present during } \\
\text { the same two-week period and represent a change from previous } \\
\text { functioning; at least one of the symptoms is either (1) depressed or } \\
\text { irritable mood or (2) loss of interest or pleasure. } \\
\text { Note: Do not include symptoms that are clearly attributable to another } \\
\text { medical condition. } \\
\text { 1.Depressed or irritable mood most of the day, nearly every day, as } \\
\text { indicated by either subjective report (e.g. feels sad, empty, hopeless) } \\
\text { or observation made by others (eg. appears tearful). } \\
\text { 2.Markedly diminished interest or pleasure in all, or almost all, activities } \\
\text { most of the day, nearly every day (as indicated by either subjective } \\
\text { account or observation). } \\
\text { 3.Significant weight loss when not dieting or weight gain, or decrease } \\
\text { or increase in appetite nearly every day, or failure to gain appropriate } \\
\text { weight. } \\
\text { 4.Insomnia or hypersomnia nearly every day. } \\
\text { 5.Psychomotor agitation or retardation nearly every day (observable by } \\
\text { others, not merely subjective feelings of restlessness or being slowed } \\
\text { down). } \\
\text { 6.Fatigue or less of energy nearly every day. } \\
\text { 7.Feelings of worthlessness or excessive or inappropriate guilt (which } \\
\text { may be delusional) nearly every day (not merely self-reproach or guilt } \\
\text { about being sick). } \\
\text { 8.Diminished ability to think or concentrate, or indecisiveness, nearly } \\
\text { every day (either by subjective account or as observed by others) } \\
\text { 9.Recurrent thoughts of death (not just fear of dying), recurrent suicidal } \\
\text { ideation without a specific plan, or a suicide attempt or a specific plan } \\
\text { for committing suicide. }\end{array}$ \\
\hline Criterion B & $\begin{array}{l}\text { The symptoms cause clinically significant distress or impairment in } \\
\text { social, occupational or other important areas of functioning. }\end{array}$ \\
\hline Criterion C & $\begin{array}{l}\text { The episode is not attributable to the physiological effects of a substance } \\
\text { or to another medical condition. }\end{array}$ \\
\hline \multicolumn{2}{|c|}{$\begin{array}{l}\text { Note: Criteria A-C represent a major depressive episode. } \\
\text { Note: Responses to a significant loss (e.g., bereavement, financial ruin, losses from a natural } \\
\text { disaster, a serious medical illness or disability) may include the feelings of intense sadness, } \\
\text { rumination about the loss, insomnia, poor appetite, and weight loss noted in Criterion A, } \\
\text { which may resemble a depressive episode. Although such symptoms may be understandable } \\
\text { or considered appropriate to the loss, the presence of a major depressive episode in addition } \\
\text { to the normal response to a significant loss should also be carefully considered. This decision } \\
\text { inevitably requires the exercise of clinical judgment based on the individual's history and the } \\
\text { cultural norms for the expression of distress in the contest of loss. }\end{array}$} \\
\hline Criterion D & $\begin{array}{l}\text { The occurrence of the major depressive episode is not better explained } \\
\text { by schizoaffective disorder, schizophrenia, schizophreniform disorder, } \\
\text { delusional disorder, or other specified and unspecified schizophrenia } \\
\text { spectrum and other psychotic disorders. }\end{array}$ \\
\hline Criterion E & $\begin{array}{l}\text { There has never been a manic episode or hypomanic episode. } \\
\text { Note: This exclusion does not apply if all of the manic-like or } \\
\text { hypomanic-like episodes are substance-induced or are attributable to the } \\
\text { physiological effects of another medical condition. }\end{array}$ \\
\hline
\end{tabular}


bulimia (32.9\%), alcohol abuse (23.5\%) and substance use (8.2\%) [24] as well as ADHD (11\%) [25]. Other comorbidities include anxiety disorders (16\%), adjustment disorders (16\%), dissociative/somatoform disorders (42\%), Cluster A (16\%) and Cluster C (29\%) disorders [26].

MDD: As per DSM 5, MDD has 9 criteria, 5 of which, including depressed or irritable mood and anhedonia, are required for diagnosis (Table 1) [9]. Compared to adults, irritability can be substituted for sad mood as the primary mood quality in youth. The community prevalence of MDD is $2 \%$ prior to puberty and $5-8 \%$ in adolescence $[27,28]$. Sex differences in teen prevalence are influenced by pubertal status. Prior to puberty, there are generally no sex differences in prevalence $[28,29]$ and in cases in which differences are identified rates of depression are higher in prepubescent males [30,31,32]. After puberty, there is a notable female preponderance in prevalence of adolescent depression that is generally consistent across clinical and epidemiologic samples $[33,34]$ and persists into adulthood [35].

Comorbidity with depression is very common in adolescent populations, with estimated rates of $42 \%$ in community samples and up to $75 \%$ in clinical samples [36]. Research suggests that comorbidities may vary with the age and gender of the individual. In younger children, anxiety disorder comorbidity is most common with depression with comorbidity rates ranging from $15-75 \%$ depending on the type of anxiety disorder [37]; Studies in pre-adolescents have found depression to be comorbid with ADHD (42\%) and disruptive behaviour disorders (22.7-83.3\%) [38,39]. For adolescent males, comorbidities include oppositional defiant disorder (ODD) and substance use disorders whereas for females in the same age group, eating disorders are more frequently comorbid with MDD [40].

Studies comparing BPD and MDD: Few studies have reported comorbidity rates of BPD and MDD. From a sample of adolescent inpatients with $\mathrm{BPD}, \mathrm{Ha}$, et al. [41] reported rates of $70.6 \%$ for comorbid mood disorders. One early study in 35 depressed adolescent inpatients estimated $30 \%$ comorbidity with $\mathrm{BPD}$, making BPD the most commonly diagnosed personality disorder in adolescents with MDD though the significance of these findings is limited by the small and clinical nature of the sample [42].

\section{Course of illness}

BPD: Research into stability and course of BPD symptoms or diagnosis in youth is increasing in volume. A longitudinal study of adolescents showed that BPD could be reliably and validly diagnosed in those as young as 12-14 years of age [43]. The ALSPAC study suggested that diagnostic stability of BPD begins at age 11-12 years [44]. A longitudinal study of females ages 14-19 from a community sample found that BPD symptoms appear to peak at age 15, decline between 15 and 18, and stay steady between 18 and 19 years of age [3]. A recent study by Conway, Hipwell and Stepp [45] challenges the notion of stability in BPD symptoms across adolescence. In their large community study of girls ages 14-20, they found that half of the variance BPD symptoms were due to time-invariant (trait) factors and the remainder to time (occasion) specific variation in symptoms.

Stability of BPD symptoms or diagnosis is difficult to assess from clinical studies where the majority of participants will be exposed to treatment. As an example, a study of the stability of adolescent BPD identified that only 3 of 14 teens initially diagnosed with BPD continued to meet BPD criteria after 3 years [46]. Adolescents $(\mathrm{N}=204)$ that presented in to an emergency room at age 14 with suicidal ideation or a suicide attempt were followed for 4 years and were classified as having "persisting" BPD (met criteria for a BPD diagnosis at both time points), "remitting" BPD (only met threshold criteria at recruitment), "emerging" BPD (only met threshold criteria at follow-up) and "never BPD" (never met threshold criteria) [47]. The majority (76\%) of adolescents were classified as having "persisting" BPD, while smaller groups met criteria at only one time point and were classified as having "remitting" (13.2\%) and "emerging" (3.4\%) BPD, respectively.

MDD: Compared to BPD, MDD typically begins in early adulthood with an average age of onset of 32 years [48]; however, half of adults with depression had their first episode of the disorder in childhood and adolescence, making specific study of the adolescent course of the disorder very important [49]. The average age of onset in adolescents is estimated to be 14.9 years [16]. The average length of a depressive episode in children and adolescents ranges from 7 to 9 months $[16,50,51]$ and majority of episodes remit within two years $[51,52,53,54]$. Childhood depression is associated with an increased risk of depression in adolescence, with reoccurrence of a depressive episode within 4 years of recovery from the first episode in 30 to $70 \%$ of cases [55]. This pattern of recurrence is especially true is cases in which there is a familial history of MDD, history of abuse, negative cognitive style and presence of additional comorbid diagnoses such as anxiety disorders and dysthymic disorder [55,56].

Studies comparing BPD and MDD: No published studies of children or adolescents have specifically compared how comorbid BPD and depression presents in children nor examined the correlates of comorbidity, however the study by Conway, Hipwell and Stepp [45] described above found a strong correlation between the longitudinal stability of IPDE-BOR items with depressive symptoms from the Child Symptom Inventory in girls across ages 14-20, demonstrating probable stable factors underlying both BPD and depressive symptoms. A longitudinal twin girl study showing high correlations $(\mathrm{r}=0.82)$ between the conditions across ages 14-20, with BPD and depression symptoms showing similar instability across this developmental stage [57]. The latter study could identify important non-shared environmental contributions to the covariation in depression and BPD symptoms suggesting the importance of life experiences to both types of symptom manifestation.

Summary: BPD and MDD differ in their persistence over the life course. Validity of childhood depression in those as young as 6 has been established [58] whereas BPD can be reliably and validly diagnosed in those as young as 12-14 years of age [20,43]. One study noted prevalence of BPD symptoms is greater in younger as opposed to older adolescents [3] whereas childhood-onset MDD tends to be recurrent and episodic in nature, likely affecting the individual well into adulthood $[59,60]$.

\section{Risk factors and correlates}

Risk factors which have been reported in important reviews of the etiology of BPD or MDD [61,62] specifically sex differences, developmental trauma (relationships with caregivers, sexual or physical abuse), and family history of psychiatric disorders were compared. We also included the clinical correlate of suicidal risk behaviours (SRBs) as they are a common feature of both MDD and BPD in adolescents.

\section{i. Sex}

BPD: There has yet to be research to systematically measure sex differences in prevalence of BPD in adolescents from community studies. Clinical studies from recent years suggest that adolescent females and males may exhibit BPD symptoms differently affecting prevalence rate estimations [63]. Females account for up to three- 
quarters of patients with BPD in clinical samples; authors suggest that boys in these settings have lesser intensity of symptoms or they do not seek treatment at comparable rates to girls $[21,64]$.

MDD: Approximately two-thirds of adolescents with depression are female, though studies generally find no sex differences in prevalence prior to puberty $[28,29]$, and in cases where differences are noted, rates of depression are higher in prepubescent males [30,31,32]. The female preponderance in prevalence of adolescent depression is generally consistent across clinical and epidemiologic samples $[33,34]$ and persists into adulthood [35]. Pubertal status, not chronological age, is the determinant of when this sex difference in depression becomes prevalent $[65,66]$. Specifically, in females, depression is linked with more mature pubertal status and early timing, whereas in males, depression is linked with less mature pubertal status and late timing [67].

Studies comparing BPD and Depression: There has yet to be research to directly compare the sex differences in prevalence of BPD versus MDD in adolescents.

\section{ii. Developmental trauma}

BPD: Evidence currently exists for a causal relationship between childhood trauma and BPD, as per Hill's criteria for causation $[68,69]$. Insecure or disorganized caregiver attachment in early life may increase one's risk for BPD, with a history of hostile or neglectful parenting being a common risk factor [21]. Individuals with BPD often report increased fear of losing their primary attachment figure, making it difficult to ascertain whether attachment difficulties precede BPD or are a result of the disorder's emotional impact [70], A recent metaanalysis examining the strength of association between childhood abuse and BPD symptoms found that report of physical abuse OR parental hostility/verbal abuse OR parental neglect were each independently associated with a 3-fold increase in risk for BPD [2] compared to the outcome of no BPD in adulthood. Report of childhood sexual abuse was associated with a 5-fold increase in risk for BPD in the same study.

MDD: Adults with MDD report more adverse childhood events in comparison to healthy controls and are more likely to endorse the experience of loss (death of a loved one) in childhood in these studies [71]. Insecure or disorganized caregiver attachment in early life has been significantly associated with childhood depression [72] or depressive symptoms in adolescents [73]. A large 17-year cohort study found that childhood maltreatment was associated with a 3 -fold increase in depression and/or suicidal risk in adolescence and young adulthood in comparison to those without history of maltreatment, with sexual abuse being the strongest predictor of both phenomena [74]. Cross-sectional data from a study of children exposed to childhood maltreatment showed that physical abuse, emotional maltreatment and a higher number of out-of-home placements were associated with an increased risk of MDD in comparison to maltreated youth who did not meet criteria for diagnosis [75].

Studies comparing BPD and Depression: There has yet to be research to directly compare the effects of trauma and caregiver attachment quality as risk factors for BPD versus MDD in adolescents.

\section{iii. Family psychopathology}

BPD: Rates of family psychopathology did not significantly differ between children with BPD and psychiatric controls in inpatient settings $[76,77,78]$. Rates did differ in outpatient psychiatric settings where $77 \%$ of youth with BPD had one or more family member(s) with any psychiatric disorder versus $44 \%$ of youth with a non-BPD [76]. Two studies reported twice the rate of substance use disorders and affective disorders in family members of youth with BPD than clinical youth without $\mathrm{BPD}$, and much higher rates of reported anti-social behaviours (23\% vs 3\%) [76] and Cluster C personality disorders [79].

Studies of offspring of parents affected by BPD demonstrate that concurrent maternal BPD when the youth is 15 years old predicts persistence of youth symptoms across ages 15 to 20 [80]. Further study of this sample of adolescents $(\mathrm{N}=295)$ found that maladaptive interactions between mother and child mediated the relationship between maternal and offspring BPD status [80]. A study of adolescent offspring found that perceived maternal rejection was significantly associated with the severity of BPD symptoms in children [79]. Only one study examining the genetic associations of BPD traits in youth specifically was located. Hankin, et al. [81] found that youth carriers of the short allele of the serotonin transporter promoter gene (5-HTTLPR) had significantly greater levels of BPD traits even after controlling for depressive symptoms.

MDD: Genetic studies of depression including both bottom-up (i.e., studying psychopathology in families of children with MDD) and top-down approaches have shown a familial influence in the development of MDD in children. A review of 10 studies of childhood depression reported a two-fold increase in prevalence of MDD in first-degree relatives of children with MDD in comparison to both healthy and non-affective psychiatric controls [82]. Additionally, they reported a relative risk/odds ratio range of 0.9-8.8 (median=2.75) of MDD in offspring of depressed parents in comparison to mentally healthy control parents and a two-fold increase in risk of MDD in offspring of depressed parents in comparison to psychiatric control parents [82]. Having two depressed parents increases risk further, as well as age of onset and severity of child depression [83,84]. Similar findings from earlier studies also suggest that later onset of depression is associated with less familial aggregation of depression [85] while earlier, adolescent onset (i.e., under age 20) is associated with a higher density of familial depression [86,87].

Studies comparing BPD and Depression: Although there has yet to be research directly comparing the effects of family psychopathology as a risk factor for BPD-only versus $\mathrm{MDD}$-only in adolescents, one study examining family psychopathology of depressed adolescents with BPD traits was located. Guilé, et al. [88] conducted a retrospective chart review to compare family psychopathology in depressed adolescents with $(\mathrm{N}=30)$ and without $(\mathrm{N}=28)$ BPD traits. Depressed adolescents with BPD traits had higher familial psychopathology including parental history of delinquency, drug abuse and personality disorders in comparison to depressed adolescents without BPD traits [88].

\section{iv. Suicide related behaviours (SRBs)}

BPD: Non-suicidal self-injury (NSSI), characterized by deliberate destruction of the body tissue but in the absence of intent to die, is the most frequently observed BPD trait in adolescents [19,21]; with a wellestablished body of research demonstrating a significant association between the presence of NSSI behaviours and BPD. For example, Nock, et al. [89] found that $51.7 \%$ of adolescent females with a history of NSSI met criteria for a diagnosis of BPD. Another large $(\mathrm{N}=441)$ clinical outpatient study of adolescents noted that the reported experience of NSSI or suicide attempt (SA) and their combination were incrementally more strongly associated with BPD diagnosis than the absence of these behaviours in patients [90]. Data for SA and completion rates in adolescents with BPD is lacking. 
MDD: NSSI is very common in depressed youth. A longitudinal study of NSSI among a large community sample of adolescents found that adolescents with a history of depression reported higher and more stable engagement in NSSI in comparison to non-depressed adolescents [91]. The Treatment of SSRI-Resistant Depression in Adolescents (TORDIA) study assessed NSSI and SA behaviours at baseline and over 24 weeks of follow-up in study participants [15]. At baseline, $47.4 \%$ of participants endorsed a history of self-injurious behaviour with NSSI being the most commonly reported. Over the course of the 24week follow-up, $7 \%$ and $11 \%$ of participants endorsed SA and NSSI behaviours, respectively, with rates of incidence highest in adolescents endorsing both NSSI+SA at baseline assessment.

Several studies have demonstrated a significant correlation between depression and behaviours with reported suicidal intent in adolescents [92]. For example, psychological autopsies comparing adolescent suicide victims to healthy controls have demonstrated a link between mood disorders (e.g. MDD) and completed suicide, especially when comorbid with substance abuse $[93,94,95]$. Similarly, depression has been linked to both suicidal ideation and SA in adolescents. A 21-year follow up of the Dunedin birth cohort $(\mathrm{N}=965)$ found that diagnosis of depression as measured yearly across ages 15 to 21 had the strongest risk for suicidal ideation (risk ratio=3:71) and suicide attempts (risk ratio=6:49) at age 21 [96]. Lifetime estimates of suicidal ideation and SA in youth with MDD are $85 \%$ and $37 \%$, respectively [97] with $20 \%$ of individuals with adolescent-onset MDD making more than one lifetime SA [98] and 2.5-7\% completing suicide by early adulthood [99].

Studies comparing BPD and Depression: Ferrara, Terrinoni and Williams [100] reported on adolescent psychiatric inpatients selected on the basis of their engagement in NSSI. Of the sample, $64.5 \%$ had BPD, $46.1 \%$ of the sample had a history of suicide attempts, and $53.8 \%$ had elevated depressive symptoms [100]. Although they measured depression and BPD in the same sample these authors did not specifically report on the impact of comorbidity on SA and SRB. In a clinical sample of adolescents, diagnoses of MDD and BPD independently increased odds for experiencing suicidal ideations by 3.79 and 2.42 times, respectively [101]. The authors note that combining both disorders in a predictive model substantially improved prediction of self-harm [101].

Summary: Evidence suggests that BPD and MDD may share similar risk factors. Both are more commonly diagnosed in females, though controversy remains over whether this represents a diagnostic bias or a true sex difference in youth with BPD. Additionally, insecure or disorganized caregiver attachment in early life may increase one's risk for both BPD and MDD. Childhood maltreatment is unfortunately common in histories of youth with MDD or BPD, with report of sexual abuse being the strongest correlate of both disorders. Family psychopathology is common in both youth with BPD and youth with MDD, with parental depression increasing the risk of both disorders in offspring and maternal BPD increasing the risk of BPD in offspring. NSSI and SA are also common clinical correlates of both BPD and MDD, especially in clinical samples of adolescents, however rates are likely greater in youth with BPD or with BPD and MDD comorbidity.

\section{Neurobiology and Neuroendocrinology}

BPD: Reduced gray matter volume was found in the left orbitofrontal cortex (OFC), dorsolateral prefrontal cortex (DLPFC), and anterior cingulate cortex (ACC) in female adolescents (14-18 years of age) with BPD compared to healthy control participants using 3T MRI [102]. Using MRI methodology, Chanen, et al. [103] also noted right-sided gray matter loss in the OFC and no significant changes in amygdalar nor hippocampal volume in adolescents with first presentation BPD $(\mathrm{N}=20)$ compared to healthy controls $(\mathrm{N}=20)$. Data from this particular sample of adolescents was further studied by various research groups. It was found that there were no notable differences in pituitary volumes in youth with BPD compared to healthy controls [104], however history of childhood trauma was associated with decreased volume ( 18\%; [104] and number of lifetime parasuicidal occurrences was associated with increased volume [105] of the pituitary. Additionally, Takahashi, et al. [106] reported no significant differences in the volume of the insular cortex between the youth with BPD and healthy controls in this sample of adolescents, though bilateral reductions in insular volumes were reported in youth with BPD that had experienced violent episodes in the previous 6 months versus those without such episodes. Lastly, Whittle, et al. [107] examined anterior cingulate (ACC) volumes in a subset $(\mathrm{N}=15)$ of adolescents from the Chanen, et al. [103] study. They reported decreased left ACC volumes in youth with BPD that correlated significantly with impulsivity scores and reports of parasuicidal behaviours, demonstrating a possible connection between insular volumes and clinical correlates of BPD in adolescents [107].

MDD: Decreased functional connectivity on resting state fMRI within the subgenual ACC-based neural network has been shown in depressed versus unaffected control adolescents; a region thought to regulate emotional processing [108]. Adolescents with MDD have been shown to have reductions in whole brain volumes in comparison to healthy age-, race- and gender-matched controls [109] with significant reductions in the volume [109] and connectivity in white matter tracts [110] of the frontal region. Adolescents with non-familial MDD had significantly larger left- but not right-subgenual prefrontal cortical volumes compared to peers with familial MDD and controls, possibly indicating abnormal prefrontal cortex maturation in those with nonfamilial MDD [111]. Depressed youth had larger amygdala relative to hippocampal volumes compared to controls and that this effect was larger in those with familial versus non-familial MDD [112]. Similarly, left hippocampal volumes in early-onset depressed adolescents were reduced by $17 \%$ in comparison to healthy control adolescents with a decreased correlation between the age of onset of depression and hippocampal volume, possibly demonstrating the role of depression development on the volume of the hippocampus over time (i.e., brain damage) [113]. In addition to changes in brain volumes and connectivity, studies of pediatric MDD have revealed a bidirectional link between depression and inflammation [114], with reductions of neurotrophic factors such as BDNF noted in children with depression [115] compared to healthy controls.

Studies comparing BPD and Depression: No studies in adolescents have directly compared youth with MDD or BPD; youth with comorbid BPD and MDD displayed reduced ACC grey matter volume (specifically in Brodmann area 24), which was associated with increased BPD severity and number of suicide attempts compared to healthy, age-matched controls [116]. Although none of these youths had non-comorbid BPD, similar findings of reduced anterior cingulated grey matter have been noted in adults with BPD as compared to healthy controls and this difference could not be explained by comorbid depression [117]. The differences in gray matter volumes observed in both adults and adolescents with comorbid BPD and depression may suggest a neurodevelopmental abnormality [116], specifically in terms of front limbic network dysfunction [118].

Summary: Reduced prefrontal cortical volumes have been reported in adolescents with BPD and MDD. Numbers of suicide attempts, 
severity of suicidal behaviours and impulsivity have also been linked with reductions in left ACC volumes in youth with BPD; in youth with MDD, decreased functional activity in the area of the ACC thought to regulate emotional processing has been observed. Depressed youth have larger amygdala relative to hippocampal volumes, with hippocampal shrinkage over time.

\section{Neuropsychology}

BPD: Although alterations in facial emotional processing have consistently been demonstrated in adults with BPD, research into facial emotional processing in children and adolescents with BPD has produced mixed results. Adolescents with BPD demonstrated stronger orienting to negative emotional stimuli in comparison to healthy controls but not youth with other psychiatric disorders [119]. No differences in facial emotion recognition were found in youth with BPD versus healthy controls [120]. Youth aged 15-24 years with BPD had higher preference for immediate gratification and greater rate of discounting the delayed reward than controls, with higher scores of impulsiveness being linked to greater discounting in the BPD group [121].

MDD: A meta-analysis reviewing 17 studies of neuropsychological testing in depressed $(\mathrm{N}=447)$ and healthy control $(\mathrm{N}=1347)$ adolescents revealed that, on average, adolescents with depression had significant impairments in inhibition capacity, phonemic verbal fluency, verbal memory, planning \& sustained attention in comparison to healthy control adolescents [122]. Maalouf, et al. [123] compared neurocognitive performance in adolescents in an acute episode of MDD $(\mathrm{N}=20)$, adolescents in remission $(\mathrm{N}=20)$ and healthy control adolescents. They found that acutely unwell adolescents demonstrated more impairments in executive function and higher scores of impulsivities in comparison to both remitting MDD and healthy control adolescents; impairments in executive function tended to increase with severity of depression and impulsivity tended to increase with severity of depression and earlier age of onset of MDD.

Studies comparing BPD and Depression: One study compared the ability to differentiate and integrate one's own perspective with that of others in youth with either full- or subsyndromal-BPD or MDD [124]. Youth with BPD had significantly lower social perspective than those with MDD and social perspective scores were better predictors of BPD status in comparison to self-report ratings of neuroticism and agreeableness, disturbed attachment and functional impairments. Thus, these findings highlight the disruptions in social cognition characteristic of BPD over MDD in youth.

Summary: Research into facial emotional processing in adolescents with BPD has been inconclusive. Youth with BPD show impaired trait impulsivity, preference for immediate gratification and delay discounting relative to healthy controls. Depressed youth clearly demonstrate deficits in executive functioning compared to healthy controls and EF deficits are worse in acute episodes of illness and in youth with early onset depression and/or higher impulsivity. Direct comparisons between BPD and MDD youth demonstrate significantly worse social cognition in those with BPD.

\section{Treatment}

BPD: Studies examining clinical impact of treatment for BPD typically enroll youth with 2 or 3 symptoms of BPD as opposed to requiring a diagnosis be present. The subsyndromal BPD group has not been specifically contrasted to the diagnostic group in terms of treatment response. Research to date has shown some benefit to early intervention programs for youth who meet criteria for a few symptoms (2 or more) of BPD [124]. Randomized controlled trials of several manualized therapies have been completed, establishing these therapies as evidence based interventions. These therapies include Dialectical Behavioural Therapy [125,126], Cognitive Analytic Therapy [127], Mentalization Based Therapy [128]. It is acknowledged that therapy must address the systems of the young person's life including family, peers, as well as the health care system, and a strong focus on psychoeducation and improving daily functioning consistent with life goals are central to the treatments.

Pharmacotherapy is not currently recommended by several expert reviews as a primary treatment for BPD in youth $[8,129,130]$. This is because there are no controlled studies on the use of medication in youth with BPD or BPD symptoms. More recently, a single trial [131] has reported significant benefit from omega-3 polyunsaturated fatty acids (PUFAs) for adolescents with BPD and psychotic features. Two observational studies have examined small ( $<15$ youth) samples of adolescents with BPD over 2-3 months. Golubchik, et al. [132] demonstrated significant benefit of Ritalin for ADHD, impulsivity, aggression and self injury in girls with comorbid ADHD and BPD. Symptom reduction across many domains of mental health symptoms was found with exposure to fluphenthixol in youth with BPD, but high rates of extrapyramidal symptoms limiting its use [133]. It has also been noted that the decision to use medication for comorbidity with BPD should be made in collaboration with the patient and the benefits of medication regularly reviewed to avoid the well documented problem of polypharmacy [130].

MDD: Treatment of unipolar depressive episodes in adolescents is conceptualized currently within a hierarchical model of care which reflects the severity of depressive symptoms at presentation. Generally, severity of depression is categorized as mild, moderate or severe, and is a reflection of symptom severity, youth functional impairment as well as number of comorbid disorders. In all severities of illness presentation, psychoeducation to the youth and family about depression, behavioural activation, attention to quality of sleep and nutrition and reduction of life stressors are components of care [134]. Milder severities of depressive symptoms are suggested to benefit potentially from an active monitoring approach with or without supportive psychotherapy with a strong behavioural activation component. Treatment for moderate severity of symptoms should include an evidence based psychotherapeutic intervention (interpersonal therapy or cognitive behavioural therapy), and possible antidepressant medication trial depending on patient characteristics [135]. It is generally considered essential for a severe depressive episode to be treated with antidepressant medications as well as evidence based psychotherapy. Several trials have been conducted for treatment of first episode of depression management [136] as well as for youth whose depressive episode has not responded to a trial of medication, or treatment refractory depression (TRD) [137]. A recent review of studies of TRD identified that approximately half of these adolescents responded to another antidepressant medication [138]. The combination of antidepressant medication and psychotherapy - either CBT or IPT - should be recommended for adolescents who present with treatment-resistant depression [138].

Despite these recommendations, it is important to note that the effect of antidepressant medication for adolescent depressive symptoms is not robust. A recent Cochrane meta-analysis notes no significant effect of antidepressant medication for the treatment of depression and a small increased risk of suicidal ideation intensifying with medication [139]. Given that only a small number of trials contributed information 
about each of the comparisons made in the review, it was not possible to draw robust conclusions from the meta-analyses, nor to establish which intervention strategy was most effective.

Co-occurring BPD and MDD: Studies of depression treatment of adolescents have not been identified which measure the impact of treatment for depression on BPD symptoms, however the opposite is not true. There have been 11 RCTs of therapeutic interventions for BPD and BPD symptoms in adolescents. Two of these have shown significant treatment effects on depressive symptoms ([140], effect size $\mathrm{d}=0.24$ at 2 years; [141], $\mathrm{d}=0.68$ at one year). Of the other 9 studies, none have identified or specifically tested a significant effect of DBT on depressive symptoms. Interestingly, of the positive studies, the magnitude of the treatment effect on depressive symptoms was very similar to the effect on BPD symptom reduction ([140], $d=0.29$ for both; [141], $d=0.70$ for both). The specific effect of BPD treatments on achieving remission in major depressive episode is not known, although large effect sizes seen in one study cited above suggest that mentalization based therapy (MBT) may be effective for the treatment of depressive episodes. Interestingly, a one year follow up of the largest RCT of DBT showed no significant difference after 104 weeks between the DBT-A and treatment as usual (TAU) groups due to improvement in the TAU group, suggesting that DBT-A may provide the most rapid treatment response and return to functioning but with comparable effects to TAU at 2 years [140].

The aforementioned studies do not exclusively include youth with diagnoses of both BPD and MDD. In recognition of the difficulty of distinguishing MDD and BPD in many youth, the high comorbidity and the need to provide treatments, Chanen and Thompson [142] have proposed a staged care model for treatment of mood disorders and BPD. They propose that in the absence of clear diagnoses, it is important to proceed using treatments that are likely to benefit and not negatively impact the comorbid symptom. All youth with subsyndromal disorders will benefit from several psychosocial interventions such as mental health literacy, parent support and education, substance abuse reduction, problem solving skills development. When syndrome (MDD or BPD) threshold is crossed, specificity in the psychotherapeutic approach is indicated as opposed to aggressive pharmacotherapy. In some instances both are indicated, but there is not adequate data to support pharmacotherapy in such instances.

\section{Summary}

Treatment of depression and BPD symptoms in adolescents should include multimodal (i.e., family, individual, and group) psychotherapeutic interventions. Interestingly, studies of youth with 2 or more BPD symptoms have shown similar effects of MBT and DBT on both borderline and depressive symptoms in the treatment groups. Whether depressive and BPD symptoms respond comparably to other treatments for depression, for example, is not known. Given that the longest studies of CBT (24 weeks; [137]), and DBT (52 weeks; [7]) have not shown significant differences between TAU and treatment groups for the primary outcome of depression or BPD symptoms, respectively, it may be important to understand the impact of untreated comorbidity (i.e., mood or anxiety) or course of comorbidities on BPD outcomes. Studies are needed which specifically evaluate this question as well as to estimate the potential harms (increased emergency care usage, increased suicidal ideation) of treatments, particularly when involving medications. As studies of depressed youth suggest that antidepressant treatment may also help with depressive symptom reduction, it is critical to evaluate the impact of medications in studies of adolescents with mood difficulties, and $\mathrm{BPD}$ and depressive symptoms should be measured jointly.

\section{Discussion}

This paper examined for evidence of distinct demographic, biological, social and treatment indicators to compare BPD and MDD in adolescence. The problem of comorbidity is real for clinicians and the need to inform diagnostic decisions with data supporting the discriminant validity of these diagnoses is great.

To date, there is little evidence in support of these two disorders having sufficiently distinctive clinical features. Higher quality evidence can be derived from studies employing direct comparison between BPD and MDD or their symptoms in samples where both disorder phenotypes are measured conjointly. Indirect comparisons regarding the disorders' risk factors come from multiple studies looking at the same outcome, but in different samples, ie. youth with depression in one study, and youth with BPD in another.

Few direct comparison studies were identified, yet all confirmed that depression or depressive symptoms are highly comorbid with BPD symptoms. Three were longitudinal studies providing data that could establish more robust evidence about the potential different versus shared risk processes for these disorders. These studies found that both BPD and MDE or their defining symptoms predicted each others' decrease with treatment [143], tend to covary over time [45] or may dissociate somewhat with depressive symptoms increasing and BPD symptoms decreasing across adolescence [57].

Other direct comparison studies have noted that in clinically impaired adolescents, the presence of BPD symptoms adds additional prediction to suicidal behaviours beyond that associated with depressive symptoms [144], however the majority of risk of suicidal behaviours is due to common variance. Greater deficits in social perception of BPD youth relative to peers with MDD have been found, and one psychotherapy (DBT) trial specifically notes conjoint improvement of BPD and MDD symptoms in youth with 2 or more BPD symptoms [7]. These studies together do not replicate findings regarding the distinctiveness of BPD and MDD in adolescents, beyond supporting a strong covariation that may be influenced by other yet to be determined factors over time.

Indirect comparison studies provide less robust evidence, but are more numerous. Across adolescence, community prevalence of BPD may not differ by sex, although prevalence of depression is significantly greater in females. The impact of puberty is not yet examined in BPD but it is a significant correlate of increasing depressive symptoms in girls. BPD may have a different adolescent course than depression in that depression severity may be episodic, and BPD symptoms reduce in severity with age. However, heterogeneity in BPD symptom course has been noted by Greenfield, et al. [47] where threshold level BPD symptoms persist throughout adolescence in a small group and attenuate in another over a 4-year period. No neuroimaging study has yet identified significant regional differences between youth with MDD versus BPD, although differences from controls are present. However, youth with BPD and/or depression appear to share reductions in volume of prefrontal structures, particularly the ACC, and volume reductions are predicted by severity of suicidal behaviours and age of onset of depressive illness.

Family psychiatric history findings are not grossly different; youth with MDD or BPD have significantly more affected family members with multiple and varied disorders compared to healthy controls with limited disorder specificity. 
In summary, the evidence is greater that these conditions have more in common than they do in difference from both direct and indirect comparisons. The evidence reviewed to date is not definitive and thus it is critical to remember that absence of difference is very different than absence of evidence of difference between BPD and MDD in youth. With studies particularly targeting evidence of difference between the symptom clusters in adolescents with respect to course of illness, treatment and other biological variables, we may soon have stronger evidence of difference or lack of difference.

\section{Implications}

As more direct comparison data is needed to answer the question regarding discriminant validity, research studies enrolling adolescents with mood disorders should measure BPD or BPD symptoms concurrently. Given the high degree of comorbidity between these disorders in tertiary clinical samples, community based studies are critical to help describe the phenomenon and impact of BPD/emotion dysregulation in developing adolescents. However, more tertiary studies are indeed required, particularly to examine the impact of interventions and their biologic correlates. This latter information will help extend the data to comparisons beyond groups identified by their diagnostic label of BPD, MDD or the comorbidity.

The current evidence leaning toward limited distinctiveness between MDD and BPD in youth is also supported by evidence of similar response to treatment in one study [7]. This does not mean that there are not important, if not critical, treatment differences that are relevant to youth with these disorders. This reality has been recognized by others who have asserted an alternative formulation for MDD and $\mathrm{BPD}$ as disorders associated with emotion dysregulation in adolescents. Recognizing that these disorders may eternally be very difficult to differentiate, the assessment and treatment approach should be staged depending on the severity of MDD or BPD symptoms at any time, and to not consider them independently. A staged model of care has been proposed where interventions to increase emotion regulation capacity in the youth (such as psychoeducation, family support, behavioural activation, sleep hygiene and substance use) and their context should be tried first, and then closely evaluate both the course of illness and the presence of persistent disorder following such interventions. These interventions may reduce the "shared noise" of adolescent mood difficulties such that distinctiveness between BPD and MDD can be better studied. It can also be argued that youth will progress more quickly up the stages of care if they have comorbid BPD as this may impact the treatment relationship in important ways, providing further evidence of validity of BPD in adolescents. Tests of this model provide a framework for studying different domains of psychopathology and impairment common and then specific to each disorder in adolescents. Such studies are needed, however are not currently published or registered as clinical trials at the time of writing.

From a methodology perspective, longitudinal studies, particularly those which seek to identify groups of youth based on their symptom course would be welcomed. It is then possible to examine differences between youth who have stable versus varying severities of symptoms over time - respecting the course of symptoms is a critical feature delineating a syndrome. Alternatively, as has been recently shown by Conway, Hipwell and Stepp [45] there is a scomponent to borderline pathology and a time varying component of symptoms that may be responsive to environmental change. It is likely that these disorders in adolescence are highly sensitive to context, and that the BPD symptoms are most responsive to context. Regardless, group definition by mood symptoms alone is overly reductionistic. More research is needed that considers a duality (each are different) and a foundation plus (mood instability plus) model.

\section{Conclusion}

This review highlights the small body of important work that has been done, and emphasizes the need for regular measurement of BPD - the most common personality disorder cluster in adolescents - in studies about depression in adolescents. More data is needed to compare BPD and MDD syndromes in youth to expand our knowledge of etiology, course and treatment of mood disorders across the lifespan.

\section{Acknowledgements}

Thank you to Debbie Hughes, RN, who helped with proofreading of the manuscript.

\section{Funding}

Part of this work was made possible through a project grant from the Ontario Mental Health Foundation (K Boylan).

\section{Declaration}

No authors have any financial or other competing interests to declare for this work.

\section{References}

1. Fossati A (2015) Diagnosing borderline personality disorder during adolescence: A review of the published literature. Scand J Child Adolesc Psychiatry Psychol 3: 5-21.

2. Winsper C, Lereya ST, Marwaha S, Thompson A, Eyden J, et al. (2016) The aetiological and psychopathological validity of borderline personality disorder in youth: A systematic review and meta-analysis. Clin Psychol Rev 44: 13-24. [Crossref]

3. Stepp SD, Keenan K, Hipwell AE, and Krueger RF (2014) The impact of childhood temperament on the development of borderline personality disorder symptoms over the course of adolescence. Borderline Personal Disord Emot Dysregul 1: 1-10. [Crossref]

4. Chanen AM, Kaess M (2012) Developmental pathways to borderline personality disorder. Curr Psychiatry Rep 14: 45-53. [Crossref]

5. Nicastro R, Prada P, Kung A-L, Salamin V, Dayer A, et al. (2016) Psychometric properties of the French borderline symptom list, short form (BSL-23). Borderline Personal Disord Emot Dysregul 3: 1-9. [Crossref]

6. Cloitre M, Garvert DW, Weiss B, Carlson EB, and Bryant RA (2014) Distinguishing PTSD, complex PTSD, and borderline personality disorder: A latent class analysis. Eur J Psychotraumatol 5: 1-10. [Crossref]

7. Mehlum L, Ramberg M, Tørmoen AJ, Haga E, Diep LM, et al. (2016) Dialectica behavior therapy compared with enhanced usual care for adolescents with repeated suicidal and self-harming behavior: Outcomes over a one-year follow-up. $J$ Am Acad Child Adolesc Psychiatry 55: 295-300. [Crossref]

8. Fonagy P, Speranza M, Luyten P, Kaess M, Hessels C, et al. (2015) ESCAP Exper Article: Borderline personality disorder in adolescence: An expert research review with implications for clinical practice. Eur Child Adolesc Psychiatry 24: 1307-1320. [Crossref]

9. American Psychiatric Association. 2013. The Diagnostic and Statistical Manual of Mental Disorders, Fifth Edition (DSM-5). Arlington, VA: American Psychiatric Publishing.

10. Zanarini MC, Frankenburg FR, Dubo ED, Sickel MA, Trikha A, et al. (1998) Axis I comorbidity of borderline personality disorder. Am J Psychiatry 155: 1733-1739. [Crossref]

11. Zanarini MC, Frankenburg FR, Hennen J, Reich DB, and Silk KR. (2004) Axis comorbidity in patients with borderline personality disorder: 6-year follow-up and prediction of time to remission. Artic Am J Psychiatry 161: 2108-2114. [Crossref]

12. Goodman M, New AS, Triebwasser J, Collins KA, and Siever L (2010) Phenotype, endophenotype, and genotype comparisons between borderline personality disorder and major depressive disorder. J Pers Disord 24: 38-59. [Crossref]

13. Pearce J, Jovev M, Hulbert C, McKechnie B, McCutcheon L, et al. (2017) Evaluation of a psychoeducational group intervention for family and friends of youth with borderline personality disorder. Borderline Personal Disord Emot Dysregul 4: 1-7. [Crossref] 
14. Jacobson CM, Gould M (2007) The epidemiology and phenomenology of non-suicidal self-injurious behavior among adolescents: A critical review of the literature. Arch Suicide Res 11: 129-147. [Crossref]

15. Asarnow JR, Porta G, Spirito A, Emslie G, Clarke G, et al. (2011) Suicide attempts and nonsuicidal self-injury in the treatment of resistant depression in adolescents: Findings from the TORDIA study. J Am Acad Child Adolesc Psychiatry 50: 772-781. [Crossref]

16. Lewinsohn PM, Clarke GN, Seeley JR, and Rohde P (1994) Major depression in community adolescents: Age at onset, episode duration, and time to recurrence. $\mathrm{J} \mathrm{Am}$ Acad Child Adolesc Psychiatry 33: 809-818. [Crossref]

17. Skodol AE (2015) Borderline personality disorder and mood disorders: Longitudinal course and interactions. 2015. In: L. W. Choi-Kain, J. G. Gunderson, eds. 2015. Borderline Personality and mood disorders: Comorbidity and controversy. New York, NY: Springer New York. pp. 175-187.

18. Robins E, Guze S (1970) Establishment of diagnostic validity in psychiatric illness: Its application to schizophrenia. Am J Psychiatry 126: 983-987. [Crossref]

19. Michonski JD, Sharp C, Steinberg L, and Zanarini MC (2013) An item response theory analysis of the DSM-IV borderline personality disorder criteria in a population-based sample of 11- to 12-year-old children. Personal Disord Theory, Res Treat 4: 15-22. [Crossref]

20. Zanarini MC, Laudate CS, Frankenburg FR, Reich DB, and Fitzmaurice G (2011) Predictors of self-mutilation in patients with borderline personality disorder: A 10-year follow-up study. J Psychiatr Res 45: 823-828. [Crossref]

21. Kaess M, Brunner R, and Chanen AM (2014) Borderline personality disorder in adolescence. Pediatrics 134: 782-793.

22. Eaton NR, Krueger RF, Keyes KM, Skodol E, Markon KE, et al. (2011) Borderline personality disorder comorbidity: Relationship to the internalizing-externalizing structure of common mental disorders. Psychol Med 41: 1041-1050. [Crossref]

23. Chanen AM, Jovev M, and Jackson HJ (2007) Focus on childhood and adolescent mental health adaptive functioning and psychiatric symptoms in adolescents with borderline personality disorder. J Clin Psychiatry 68: 297-306.

24. Cailhol, L., Gicquel, L. and Raynaud, J-P. 2015. Borderline personality disorder in adolescents: 2015 edition. J. M. Rey, ed. Geneva: International Association for Child and Adolescent Psychiatry and Allied Professions.

25. Speranza M, Revah-Levy A, Cortese S, Falissard B, Pham-Scottez A, et al. (2011) ADHD in adolescents with borderline personality disorder. BMC Psychiatry 11: 158. [Crossref]

26. Kaess M, von Ceumern-Lindenstjerna I-A, Parzer P, Chanen A, Mundt C, et al. (2013) Axis I and II comorbidity and psychosocial functioning in female adolescents with borderline personality disorder. Psychopathology 46: 55-62. [Crossref]

27. Kessler RC, Berglund P, Demler O, Jin R, Merikangas KR, et al. (2005) Lifetime prevalence and age-of-onset distributions of DSM-IV disorders in the national comorbidity survey replication. Arch Gen Psychiatry 62: 593-602. [Crossref]

28. Son SE, Kirchner JT (2000) Depression in children and adolescents. Am Fam Physician 1562: 2297-2308.

29. Hankin BL, Abramson LY (2001) Development of gender differences in depression: An elaborated cognitive vulnerability-transactional stress theory. Psychol Bull 127: 773796. [Crossref]

30. Cyranowski JM, Frank E, Young E, and Shear MK (2000) Adolescent onset of the gender difference in lifetime rates of major depression: A theoretical model. Arch Gen Psychiatry 57: 21-27. [Crossref]

31. Hankin BL, Abramson LY, Moffitt TE, Silva PA, McGee R, et al. (1998) Development of depression from preadolescence to young adulthood: Emerging gender differences in a 10-year longitudinal study. J Abnorm Psychol 107: 128-140. [Crossref]

32. Anderson JC, Williams S, McGee R, and Silva PA (1987) DSM-III disorders in preadolescent children prevalence in a large sample from the general population. Arch Gen Psychiatry 44: 69-76. [Crossref]

33. Faravelli C, Scarpato MA, Castellini G, and Lo Sauro C (2013) Gender differences in depression and anxiety: The role of age. Psychiatry Res 210: 1301-1303. [Crossref]

34. Hyde JS, Mezulis AH, and Abramson LY (2008) The ABCs of depression: Integrating affective, biological, and cognitive models to explain the emergence of the gender difference in depression. Psychol Rev 115: 291-313. [Crossref]

35. Maier E, Gansicke M, Gater R, Rezaki M, Tiemens B, et al. (1999) Gender differences in the prevalence of depression: A survey in primary care. $J$ Affect Disord 53: 241-252. [Crossref]
36. Garber, J., Rao, U. 2014. Depression in children and adolescents. In: M. Lewis, K. D. Rudolph, eds. 2014. Handbook of developmental psychopathology. Boston, MA: Springer US. pp. 489-520.

37. Cummings CM, Caporino NE, and Kendall PC (2014) Comorbidity of anxiety and depression in children and adolescents: 20 years after. Psychol Bull 140: 816-845. [Crossref]

38. Luby JL, Heffelfinger AK, Mrakotsky C, Brown KM, Hessler MJ, et al (2003) The clinical picture of depression in preschool children. J Am Acad Child Adolesc Psychiatry 42: 340-348. [Crossref]

39. Angold A, Costello EJ (1993) Depressive comorbidity in children and adolescents Empirical, theoretical, and methodological issues. Am J Psychiatry 150: 1779-1791. [Crossref]

40. Merikangas KR, Nakamura EF, and Kessler RC (2009) Epidemiology of menta disorders in children and adolescents. Dialogues Clin Neurosci 11: 7-20. [Crossref]

41. Ha C, Balderas JC, Zanarini MC, Oldham J, and Sharp C (2014) Psychiatric comorbidity in hospitalized adolescents with borderline personality disorder. J Clin Psychiatry 75: 457-64. [Crossref]

42. Marton P, Korenblum M, Kutcher S, Stein B, Kennedy B, et al. (1989) Personality dysfunction in depressed adolescents. Can J Psychiatry 34: 810-813. [Crossref]

43. Glenn CR, Klonsky D (2013) Reliability and validity of borderline personality disorder in hospitalized adolescents. J Can Acad Child Adolesc Psychiatry 22: 206-211. [Crossref]

44. Zanarini MC, Horwood J, Wolke D, Waylen A, Fitzmaurice G, et al. (2011) Prevalence of DSM-IV borderline personality disorder in two community samples: 6,330 English 11-year olds and 34,653 American adults. J Pers Disord 25: 607-619. [Crossref]

45. Conway CC, Hipwell AE, and Stepp SD (2017) Seven-year course of borderline personality disorder features: Borderline pathology is as unstable as depression during adolescence. Clin Psychol Sci 5: 742-749. [Crossref]

46. Meijer M, Goedhart AW, and Treffers DA (1998) Personality disorder in adolescence. J Pers Disord 12: 13-22.

47. Greenfield B, Henry M, Lis E, Slatkoff J, Guilé J-M, et al. (2015) Correlates, stability and predictors of borderline personality disorder among previously suicidal youth. Eur Child Adolesc Psychiatry 24: 397-406. [Crossref]

48. Kessler RC, Berglund P, Demler O, Jin R, Merikangas KR, et al. (2005) Lifetime prevalence and age-of-onset distributions of DSM-IV disorders in the national comorbidity survey replication. Arch Gen Psychiatry 62: 593-602. [Crossref]

49. Burke KC, Burke JD, Rae DS, and Regier DA (1991) Comparing age at onset of major depression and other psychiatric-disorders by birth cohorts in 5 United-States community populations. Arch Gen Psychiatry 48: 789-795. [Crossref]

50. Birmaher B, Ryan ND, Williamson DE, Brent DA, Kaufman J, et al. (1996) Childhood and adolescent depression: A review of the past 10 years. Part I. J Am Acad Child Adolesc Psychiatry 35: 1427-1439. [Crossref]

51. Kovacs M, Feinberg TL, Crouse-Novak MA, Paulauskas SL, and Finkelstein R (1984) Depressive disorders in childhood: I. A longitudinal prospective study of characteristics and recovery. Arch Gen Psychiatry 41: 229-237. [Crossref]

52. McCauley E, Myers K, Mitchell J, Calderon R, Schloredt K, et al. (1993) Depression in young people: Initial presentation and clinical course. $J$ Am Acad Child Adolesc Psychiatry 32: 714-722. [Crossref]

53. Sanford M, Szatmari P, Spinner M, Munroe-Blum H, Jamieson E, et al. (1995) Predicting the one-year course of adolescent major depression. $J$ Am Acad Child Adolesc Psychiatry 34: 1618-1628. [Crossref]

54. Strober M, Lampert C, Schmidt S, and Morrell W (1993) The course of major depressive disorder in adolescents: I. Recovery and risk of manic switching in a followup of psychotic and nonpsychotic subtypes. J Am Acad Child Adolesc Psychiatry 32: 34-42. [Crossref]

55. Birmaher B, Arbelaez C, and Brent D (2002) Course and outcome of child and adolescent major depressive disorder. Child Adolesc Psychiatr Clin N Am 11: 619-637. [Crossref]

56. Lewinsohn PM, Rohde P, Klein DN, and Seeley JR (1999) Natural course of adolescent major depressive disorder: I. Continuity into young adulthood. $J$ Am Acad Child Adolesc Psychiatry 38: 56-63. [Crossref]

57. Bornovalova MA, Verhulst B, Webber T, McGue M, Iacono WG, et al. (2017) Genetic and environmental influences on the codevelopment among borderline personality disorder traits, major depression symptoms, and substance use disorder symptoms from adolescence to young adulthood. Dev Psychopathol Apr 2017: 1-17. [Crossref] 
58. Luby JL (2009) Early childhood depression. Am J Psychiatry 166: 974-979. [Crossref]

59. Thapar A, Collishaw S, Pine DS, and Thapar AK (2012) Depression in adolescence. Lancet 379: 1056-1067. [Crossref]

60. Emslie GJ, Mayes TL, Laptook RS, and Batt M (2003) Predictors of response to treatment in children and adolescents with mood disorders. Psychiatr Clin North Am 26: 435-456. [Crossref]

61. Wells VE, Deykin EY, and Klerman GL (1985) Risk factors for depression in adolescence. Psychiatry Dev 3: 83-108. [Crossref]

62. Lewinsohn PM, Rohde P, and Seeley JR (1998) Major depressive disorder in older adolescents: Prevalence, risk factors, and clinical implications. Clin Psychol Rev 18: 765-794. [Crossref]

63. Chang B, Sharp C, and Ha C (2011) The criterion validity of the borderline personality features scale for children in an adolescent inpatient setting. J Pers Disord 25: 492-503. [Crossref]

64. Paris, J. 2014. A history of research on borderline personality disorder in childhood and adolescence. In: C. Sharp, J. Tackett, eds. 2014. Handbook of borderline personality disorder in children and adolescents. New York, NY: Springer. pp. 9-16.

65. Angold A, Costello EJ, and Worthman C (1998) Puberty and depression: The roles of age, pubertal status and pubertal timing. Psychol Med 28: 51-61. [Crossref]

66. Hayward C, Gotlib IH, Schraedley PK, and Litt IF (1999) Ethnic differences in the association between pubertal status and symptoms of depression in adolescent girls. $J$ Adolesc Heal 25: 143-149. [Crossref]

67. Conley CS, Rudolph KD (2009) The emerging sex difference in adolescent depression: Interacting contributions of puberty and peer stress. Dev Psychopathol 21: 593-620. [Crossref]

68. Hill BA (1965) The enviroment and disease: Association or causation? Proc R Soc Med 58: 295-300. [Crossref]

69. Ball JS, Links PS (2009) Borderline Personality disorder and childhood trauma: Evidence for a causal relationship. Curr Psychiatry Rep 11: 63-68. [Crossref]

70. Lieb K, Zanarini MC, Schmahl C, Linehan MM, and Bohus M (2004) Borderline personality disorder. Lancet 364: 453-461.

71. Horesh N, Sever J, and Apter A (2003) A comparison of life events between suicidal adolescents with major depression and borderline personality disorder. Compr Psychiatry 44: 277-283. [Crossref]

72. Abela JRZ, Hankin BL, Haigh EAP, Adams P, Vinokuroff T, et al. (2005) Interpersonal vulnerability to depression in high-risk children: The role of insecure attachment and reassurance seeking. J Clin Child Adolesc Psychol 34: 182-192. [Crossref]

73. Hankin BL (2006) Adolescent depression: Description, causes, and interventions. Epilepsy Behav 8: 102-114. [Crossref]

74. Brown J, Cohen P, Johnson J, and Smailes E (1999) Childhood abuse and neglect: Specificity of effects on adolescent and young adult depression and suicidality. $\mathrm{J} \mathrm{Am}$ Acad Child Adolesc Psychiatry 38: 1490-1496. [Crossref]

75. Kaufman J (1991) Depressive disorders in maltreated children. J Am Acad Child Adolesc Psychiatry 30: 257-265. [Crossref]

76. Goldman SJ, D'Angelo EJ, and DeMaso DR (1993) Psychopathology in the families of children and adolescents with borderline personality disorder. Am J Psychiatry 150: 1832-1835. [Crossref]

77. Greenman DA, Gunderson JG, Cane M, and Saltzman PR (1986) An examination of the borderline diagnosis in children. Am J Psychiatry 143: 998-1003. [Crossref]

78. Ludolph PS, Westen D, Misle B, Jackson A, Wixom J, et al. (1990) The borderline diagnosis in adolescents: Symptoms and developmental history. Am J Psychiatry 147: 470-476. [Crossref]

79. Schuppert H, Albers CJ, Minderaa RB, Emmelkamp PM, and Nauta MH (2012) Parental rearing and psychopathology in mothers of adolescents with and without borderline personality symptoms. Child Adolesc Psychiatry Ment Health 6: 29. [Crossref]

80. Reinelt E, Stopsack M, Aldinger M, Ulrich I, Grabe HJ, et al. (2014) Longitudinal transmission pathways of borderline personality disorder symptoms: From mother to child? Psychopathology 47: 10-16. [Crossref]

81. Hankin BL, Barrocas AL, Jenness J, Oppenheimer CW, Badanes LS, et al. (2011) Association between 5-HTTLPR and borderline personality disorder traits among youth. Front Psychiatry 2: 1-7. [Crossref]
82. Rice F, Harold G, and Thapar A (2002) The aetiology of childhood depression: A review of genetic influences. J Child Psychol Psychiatry 43: 65-79. [Crossref]

83. Lieb R, Isensee B, Hofler M, Pfister H, and Wittchen HU (2002) Parental major depression and the risk of depression and other mental disorders in offspring: A prospective-longitudinal community study. Arch Gen Psychiatryeneral Psychiatry 59: 365-374. [Crossref]

84. Séguin M, Manion I, Cloutier P, McEvoy L, and Cappelli M (2003) Adolescent depression, family psychopathology and parent/child relations: A case control study. Can Child Adolesc Psychiatry Rev 12: 1-8. [Crossref]

85. Brodaty H, Peters K, Boyce P, Hickie I, Parker G, et al. (1991) Age and depression. $J$ Affect Disord 23: 137-149.

86. Weissman MM, Wickramaratne P, Merikangas KR, Leckman JF, Prusoff, BA, et al. (1984) Onset of major depression in early adulthood increased familial loading and specificity. Arch Gen Psychiatry 41: 1136-1143. [Crossref]

87. Williamson DE, Ryan ND, Birmaher B, Dahl RE, Kaufman J, et al. (1995) A casecontrol family history study of depression in adolescents. Child Adolesc Psychiatry 34 : 1596-1607. [Crossref]

88. Guilé JM, Huynh C, Breton JJ, De La Rivière, Sébastien G, Berthiaume C, et al. (2016) Familial and clinical correlates in depressed adolescents with borderline personality disorder traits. Front Pediatr 4: 1-8. [Crossref]

89. Nock MK, Joiner TE, Gordon KH, Lloyd-Richardson E, and Prinstein MJ (2006) Nonsuicidal self-injury among adolescents: Diagnostic correlates and relation to suicide attempts. Psychiatry Res 144: 65-72. [Crossref]

90. Muehlenkamp JJ, Ertelt TW, Miller AL, and Claes L (2011) Borderline personality symptoms differentiate non-suicidal and suicidal self-injury in ethnically diverse adolescent outpatients. J Child Psychol Psychiatry Allied Discip 52: 148-155. [Crossref]

91. Barrocas AL, Giletta M, Hankin BL, Prinstein MJ, and Abela JRZ (2014) Nonsuicidal self-injury in adolescence: Longitudinal course, trajectories, and intrapersonal predictors. J Abnorm Child Psychol 43: 369-380. [Crossref]

92. Cash SJ, and Bridge JA (2009) Epidemiology of youth suicide and suicidal behavior. Curr Opin Pediatr 21: 613-619. [Crossref]

93. Brent D, Baugher M, Bridge J, Chen T, and Chiappetta L (1999) Age- and sex-related risk factors for adolescent suicide. J Am Acad Child Adolesc Psychiatry 38: 1497-1505. [Crossref]

94. Shafii M, Steltz-Lenarsky J, Derrick AM, Beckner C, and Whittinghill JR (1988) Comorbidity of mental disorders in the post-mortem diagnosis of completed suicide in children and adolescents. J Affect Disord 15: 227-233. [Crossref]

95. Shaffer D, Gould MS, Fisher P, Trautman P, Moreau D, et al. (1996) Psychiatric diagnosis in child and adolescent suicide. Arch Gen Psychiatry 53: 339-348. [Crossref]

96. Fergusson DM, Woodward LJ, and Horwood LJ (2000) Risk factors and life processes associated with the onset of suicidal behaviour during adolescence and early adulthood. Psychol Med 30: 23-39. [Crossref]

97. Kovacs M, Goldston D, and Gatsonis C (1993) Suicidal behaviors and childhood-onset depressive disorders: A longitudinal investigation. $J$ Am Acad Child Adolesc Psychiatry 32: 8-20. [Crossref]

98. Harrington R, Bredenkamp D, Groothues C, Rutter M, Fudget H, et al. (1994) Adult outcomes of childhood and adolescent depression. III Links with suicidal behaviours. $J$ Child Psychol Psychiatry 35: 1309-1319. [Crossref]

99. Harrington R (1990) Adult outcomes of childhood and adolescent depression. Arch Gen Psychiatry 47: 465-473.

100. Ferrara M, Terrinoni A, and Williams R (2012) Non-suicidal self-injury (NSSI) in adolescent inpatients: Assessing personality features and attitude toward death. Child Adolesc Psychiatry Ment Health 6: 1-8. [Crossref]

101. Sharp C, Green KL, Yaroslavsky I, Venta A, Zanarini MC, et al. (2012) The incremental validity of borderline personality disorder relative to major depressive disorder for suicidal ideation and deliberate self-harm in adolescents. J Pers Disord 26: 927-938. [Crossref]

102. Brunner R, Henze R, Parzer P, Kramer J, Feigl N, et al. (2010) Reduced prefronta and orbitofrontal gray matter in female adolescents with borderline personality disorder: Is it disorder specific? Neuroimage 49: 114-120. [Crossref]

103. Chanen AM, Velakoulis D, Carison K, Gaunson K, Wood SJ, et al. (2008) Orbitofrontal, amygdala and hippocampal volumes in teenagers with firstpresentation borderline personality disorder. Psychiatry Res - Neuroimaging 163: 116-125. [Crossref] 
104. Garner B, Chanen AM, Phillips L, Velakoulis D, Wood SJ, et al. (2007) Pituitary volume in teenagers with first-presentation borderline personality disorder Psychiatry Res - Neuroimaging 156: 257-261. [Crossref]

105. Jovev M, Garner B, Phillips L, Velakoulis D, Wood SJ, et al. (2008) An MRI study of pituitary volume and parasuicidal behavior in teenagers with first-presentation borderline personality disorder. Psychiatry Res - Neuroimaging 162: 273-277. [Crossref]

106. Takahashi T, Chanen AM, Wood SJ, Yücel M, Tanino R, et al. (2009). Insular cortex volume and impulsivity in teenagers with first-presentation borderline personality disorder. Prog Neuro-Psychopharmacology Biol Psychiatry 33: 1395-1400. [Crossref]

107. Whittle S, Chanen AM, Fornito A, McGorry PD, Pantelis C, et al. (2009). Anterior cingulate volume in adolescents with first-presentation borderline personality disorder. Psychiatry Res - Neuroimaging 172: 155-160. [Crossref]

108. Cullen KR, Gee DG, Klimes-Dougan B, Gabbay V, Hulvershorn L, et al. (2009) A preliminary study of functional connectivity in comorbid adolescent depression. Neurosci Lett 460: 227-231. [Crossref]

109. Steingard RJ, Renshaw PF, Hennen J, Lenox M, Cintron CB, et al. (2002) Smaller frontal lobe white matter volumes in depressed adolescents. Biol Psychiatry 52: 413417. [Crossref]

110. Cullen KR, Klimes-Dougan B, Muetzel R, Mueller BA, Camchong J, et al. (2010) Altered white matter microstructure in adolescents with major depression: A preliminary study. J Am Acad Child Adolesc Psychiatry 49: 173-183. [Crossref]

111. Nolan CL, Moore GJ, Madden R, Farchione T, Bartoi M, et al. (2002) Prefrontal Cortical Volume in Childhood-Onset Major Depression. Arch Gen Psychiatry 59: 173-179. [Crossref]

112. MacMillan S, Szeszko PR, Moore GJ, Madden R, Lorch E, et al. (2003) Increased Amygdala: Hippocampal Volume Ratios Associated with Severity of Anxiety in Pediatric Major Depression. J Child Adolesc Psychopharmacol 13: 65-73. [Crossref]

113. MacMaster FP and Kusumakar V (2004) Hippocampal volume in early onset depression. BMC Med 2: 1-6. [Crossref]

114. Rao U (2013) Biomarkers in pediatric depression. Depress Anxiety 30: 787-791. [Crossref]

115. Pallavi P, Sagar R, Mehta M, Sharma S, Subramanium A, et al. (2013) Serum neurotrophic factors in adolescent depression: Gender difference and correlation with clinical severity. J Affect Disord 150: 415-423. [Crossref]

116. Goodman M, Hazlett EA, Avedon JB, Siever DR, and Chu KW, et al. (2011). Anterior cingulate volume reduction in adolescents with borderline personality disorder and co-morbid major depression. J Psychiatr Res 45: 803-807. [Crossref]

117. Hazlett EA, New AS, Newmark R, Haznedar MM, Lo JN, et al. (2005) Reduced anterior and posterior cingulate gray matter in borderline personality disorder. Biol Psychiatry 58: 614-623. [Crossref]

118. Leichsenring F, Leibing E, Kruse J, New AS, and Leweke F. (2011) Borderline personality disorder. Lancet. 377: 74-84

119. von Ceumern-Lindenstjerna IA, Brunner R, Parzer P, Mundt C, Fiedler P, et al. (2010) Initial orienting to emotional faces in female adolescents with borderline personality disorder. Psychopathology 43: 79-87. [Crossref]

120. Jovev M, Chanen A, Green M, Cotton S, Proffitt T, et al. (2011) Emotional sensitivity in youth with borderline personality pathology. Psychiatry Res 187: 234-240. [Crossref]

121. Lawrence KA, Allen JS, and Chanen AM (2010) Impulsivity in borderline personality disorder: Reward-based decision-making and its relationship to emotional distress. $J$ Pers Disord 24: 786-799. [Crossref]

122. Wagner S, Müller C, Helmreich I, Huss M, and Tadić A (2015) A meta-analysis of cognitive functions in children and adolescents with major depressive disorder. Eur Child Adolesc Psychiatry 24: 5-19. [Crossref]

123. Maalouf FT, Brent D, Clark L, Tavitian L, McHugh RM, et al. (2011) Neurocognitive impairment in adolescent major depressive disorder: State vs. trait illness markers. $J$ Affect Disord 133: 625-632. [Crossref]

124. Jennings TC, Hulbert CA, Jackson HJ, and Chanen AM (2012) Social perspective coordination in youth with borderline personality pathology. J Pers Disord 26: 126140. [Crossref]

125. Klein DA, Miller AL (2011) Dialectical behavior therapy for suicidal adolescents with borderline personality disorder. Child Adolesc Psychiatr Clin N Am 20: 205216. [Crossref]
126. Miller AL, Rathus JH, Linehan MM, Wetzler S, Leigh E (1997) Dialectical behavior therapy adapted for suicidal adolescents. $J$ Psychiatr Pract 32: 146-157.

127. Ryle A, Kerr IB (2003) Cognitive analytic therapy. Br J Psychiatry 183: 79.

128. Bateman A, Fonagy P (2009) Randomized controlled trial of outpatient mentalizationbased treatment versus structured clinical management for borderline personality disorder. Am J Psychiatry 166: 1355-1364. [Crossref]

129. Sharp C, Fonagy P (2015) Practitioner Review: Borderline personality disorder in adolescence - Recent conceptualization, intervention, and implications for clinical practice. J Child Psychol Psychiatry Allied Discip 56: 1266-1288. [Crossref]

130. Chanen AM, Thompson KN (2016) Prescribing and borderline personality disorder Aust Prescr 39: 49-53. [Crossref]

131. Amminger GP, Schafer MR, Papageorgiou K, Klier C, Cotton S, et al. (2010) Long-chain omega-3 fatty acids for indicated prevention of psychotic disorders: A randomized, placebo-controlled trial. Arch Gen Psychiatry 67: 146-154. [Crossref]

132. Golubchik P, Sever J, Zalsman G, and Weizman A (2008) Methylphenidate in the treatment of female adolescents with cooccurrence of attention deficit/hyperactivity disorder and borderline personality disorder: A preliminary open-label trial. Int Clin Psychopharmacol 23: 228-231. [Crossref]

133. Kutcher S, Papatheodorou G, Reiter S, and Gardner D (1995) The successful pharmacological treatment of adolescents and young adults with borderline personality disorder: A preliminary open trial of flupenthixol. J Psychiatry Neurosci 20: 113-118. [Crossref]

134. Garland JE, Kutcher S, Virani A, and Elbe D (2016) Update on the use of SSRIs and SNRIs with children and adolescents in clinical practice. $J$ Can Acad Child Adolesc Psychiatry 25: 4-10. [Crossref]

135. Hopkins K, Crosland P, Elliott N, and Bewley S (2015) Diagnosis and managemen of depression in children and young people: Summary of updated NICE guidance. BMJ 350: 824. [Crossref]

136. Kennard B, Silva S, Vitiello B, Curry J, Kratochvil C, et al. (2006) Remission and residual symptoms after short-term treatment in the Treatment of Adolescents with Depression Study (TADS). J Am Acad Child Adolesc Psychiatry 45: 1404-1411. [Crossref]

137. Emslie GJ, Mayes T, Porta G, Vitiello B, Clarke G, et al. (2010) Treatment of Resistant Depression in Adolescents (TORDIA): Week 24 outcomes. Am J Psychiatry 167: 782-791. [Crossref]

138. Zhou X, Michael KD, Liu Y, Del Giovane C, Qin B, et al. (2014) Systematic review of management for treatment-resistant depression in adolescents. BMC Psychiatry 14: 340. [Crossref]

139. Hetrick SE, McKenzie JE, Cox GR, Simmons MB, and Merry SN (2012) Newer generation antidepressants for depressive disorders in children and adolescents. Cochrane Database of Systematic Reviews 11: CD004851 [Crossref]

140. Mehlum L, Tørmoen AJ, Ramberg M, Haga E, Diep LM, et al. (2014) Dialectical behavior therapy for adolescents with repeated suicidal and self-harming behavior: A randomized trial. J Am Acad Child Adolesc Psychiatry 53: 1082-1091. [Crossref]

141. Rossouw TI, Fonagy P (2012) Mentalization-based treatment for self-harm in adolescents: A randomized controlled trial. J Am Acad Child Adolesc Psychiatry 51: 1304-1313. [Crossref]

142. Chanen A. M., Thompson, K. 2015. Borderline personality and mood disorders: Risk factors, precursors, and early signs in childhood and youth. 2015. In: L.W. ChoiKain, J.G. Gunderson, eds) Borderline Personality and Mood Disorders: Comorbidity and Controversy. New York, NY: Springer New York. pp. 155-174.

143. Strandholm T, Kiviruusu O, Karlsson L, Pankakoski M, Pelkonen M, et al. (2017) Stability and change in personality disorder symptoms in 1-year follow-up of depressed adolescent outpatients. J Nerv Ment Dis 205: 15-22.

144. Sharp, C. 2014. The social-cognitive basis of BPD: A theory of hypermentalizing In: C. Sharp, J. Tackett, eds. 2014. Handbook of borderline personality disorder in children and adolescents. New York, NY: Springer. pp. 211-225.

Copyright: (C)2017 Boylan K. This is an open-access article distributed under the terms of the Creative Commons Attribution License, which permits unrestricted use, distribution, and reproduction in any medium, provided the original author and source are credited. 